\title{
DISPERSÃO URBANA E TRANSPORTE PÚBLICO NA REGIÃO METROPOLITANA DE BELÉM: UMA ANÁLISE DE CASTANHAL E SANTA IZABEL DO PARÁ
}

\section{URBAN DISPERSION AND PUBLIC TRANSPORT IN METROPOLITAN REGION OF BELÉM: AN ANALYSIS OF CASTANHAL AND SANTA IZABEL DO PARÁ}

\author{
Gabriel Augusto Nogueira dos Santos ${ }^{1}$ \\ Ricardo José Batista Nogueira²
}

\section{Resumo}

A configuração espacial das metrópoles amazônicas é diferenciada principalmente pela sua dispersão, a partir da necessidade de uso e ocupação do solo. Nesse contexto, as cidades de Castanhal e Santa Izabel do Pará apresentam um contexto diferenciado em relação a metrópole, neste caso, Belém. Apesar das inúmeras relações de dependência, os municípios em questão construíram novas redes e relações, baseadas também na integração juntamente com a região do Nordeste Paraense, vinculada em conceituações históricas $e$ econômicas. A pesquisa foi desenvolvida entre os meses de fevereiro e março de 2018, é relacionada com a abordagem entre a relação estado x agente empresarial e a organização do sistema de transporte. A partir disso, nota-se a existência de inúmeros circuitos existentes, envolvendo questões formais e informais se tornaram presentes, principalmente no transporte de passageiros. Nota-se, portanto que influenciados pelas novas formas de uso e ocupação do solo, esses formatos de transporte ganham forças, aliados ou não a presença do poder público e influenciando nos fluxos e fixos da metrópole e das centralidades. Palavras-Chave: metrópole, dispersão urbana, transporte coletivo, circuito superior e inferior

\section{Abstract}

The spatial configuration in Amazonia metropolises differentiated mainly by its dispersion, based on the need for land use and occupation. In this context, the cities of Castanhal and Santa Izabel do Pará features a different context in relation to Belém. Despite the countless dependency relationships, the municipalities in question built new networks and relationships, also based on integration along with the Northeast region, linked to historical and economic concepts. The search developed in February and March and related about relationship to government $x$ business agent. From this, the numerous existing circuits, involving formal and informal issues, became present, mainly in passenger transport. It is noted, therefore, that influenced by the new forms of land use and occupation, these transport formats gain strength, allied or not with the presence of public power and influencing the flows and landmarks of the metropolis and centralities.

Key-words: metropolis, urban dispersion, collective transport, upper and lower circuit

\section{INTRODUÇÃO}

O surgimento de novas centralidades na região Amazônica, também é destacada também pelo processo de urbanização difusa existente principalmente a partir dos anos 1970. Destaca nesse contexto, o surgimento da Região Metropolitana de Belém, criada em 1973, na qual sofreu diversos processos até a sua

\footnotetext{
${ }^{1}$ Mestrando em Geografia pela Universidade Federal do Amazonas. Graduado em Geografia pela Universidade Federal do Amazonas e Graduando em Tecnologia em Logística pelo Instituto Federal de Educação, Ciência e Tecnologia do Amazonas. E-mail: nogueira.gabrie101@gmail.com

${ }^{2}$ Doutor em Geografia Humana pela Universidade de São Paulo. Professor Titular do Departamento de Geografia da Universidade Federal do Amazonas e do Programa de Pós-Graduação em Geografia. E-mail: nogueiraricardo@uol.com.br
} 


\section{Dispersão urbana e transporte público na Região Metropolitana de Belém: \\ Uma análise de Castanhal e Santa Izabel do Pará}

configuração atual, datada de 2011, com a inserção de Castanhal, devido as relações institucionais e as redes de fluxos e fixos existentes.

A concepção dos espaços metropolizados, está relacionado principalmente as configurações determinadas pelo poder público. Entretanto Lencioni (2013), Ribeiro (2015) e Ribeiro e Amaral (2016, p.79), destacam nesse processo, o surgimento de novas centralidades e sub-centralidades urbanas. No âmbito da Região Amazônica, é destacada a sua complexidade, no que tange ao surgimento de centralidades regionais e também, novas configurações espaciais.

A partir disso, os novos significados de dispersão metropolitana passam a surgir nesse contexto. Destaca na situação da Região Metropolitana de Belém, os municípios de Santa Izabel do Pará e Castanhal, apesar da sua distância fora do cinturão de expansão dessa área, como os municípios de Ananindeua, Marituba e Benevides. Neste âmbito, é importante destacar Castanhal e Santa Izabel do Pará, que apesar da forte ligação com a região nordeste do Pará, envolve fluxos e fixos para a capital. Alves (2012, p.18), aspectos envolvendo uma centralidade sub-regional ou uma sub-centralidade metropolitana, a partir das dispersões territoriais.

O artigo em questão, é fruto da Monografia intitulada "Entre idas e vindas: estudo de caso dos Sistemas de Transporte de Manaus e Belém", cujos objetivos estão vinculados as seguintes concepções: em aspectos gerais, a abordagem relacionada entre a atuação reguladora do estado em relação as empresas de transportes, a partir da organização do sistema e distribuição das empresas operantes, tanto em formato espacial, englobando o conceito de território e poder no sistema de transporte, além da distribuição organizacional das empresas (linhas, bairros e cidades operantes).

Com isso, o artigo vem como proposta, a compreensão dessa distribuição empresarial nos municípios de Castanhal e Santa Izabel do Pará, cujo processo organizacional e de operação do sistema se difere dos municípios mais próximos de Belém, inseridos nas áreas de expansão. Nesse processo, é importante salientar o processo de dispersão urbana e os movimentos pendulares existentes, como aspectos diferenciais na organização e atuação das empresas de transporte, além das diferentes relações frente com o poder público.

\section{ASPECTOS METODOLÓGICOS}

A organização do trabalho é relacionada principalmente a uma concomitância de métodos. Lakatos e Marconi (2019, p.90), destaca nesse processo a utilização de diversos métodos e também, metodologias para a estruturação da pesquisa e posteriormente, a sistematização da mesma. Portanto, a pesquisa foi dividida nas seguintes conjunturas:

1. Revisão de Literatura, no âmbito da Geografia Urbana e Engenharia de Transportes, para posterior sistematização; 


\section{Dispersão urbana e transporte público na Região Metropolitana de Belém:}

Uma análise de Castanhal e Santa Izabel do Pará

2. Levantamento documental em relação a leis e ordens de serviço no sistema de transportes disponibilizadas pelos órgãos gestores (Agência Reguladora e Controle de Serviços Públicos do Pará, além das Prefeituras de Castanhal e Santa Izabel do Pará);

3. Pesquisa de campo realizada nos municípios nos meses de fevereiro e março de 2018 nas cidades em questão para visitas aos órgãos gestores e as empresas operantes;

4. Elaboração de produtos cartográficos e sistematizações das documentações e dos dados obtidos em campo;

Destaca-se nessa conjuntura, em relação aos três aspectos citados, envoltos em observações sistemáticas e assistemáticas, além de uma participação não-estruturada juntamente aos trabalhadores e usuários do sistema de transporte. No quarto aspecto, é destacado um agrupamento dos dados em aspectos cartográficos, vinculados a aspectos qualitativos da pesquisa, no que tange a participação empresarial e também, das necessidades de demandas e organização do poder público na organização e eficiência do sistema de transporte.

\section{FORMAÇÃO DAS CIDADE E DISPERSÃO URBANA NA AMAZÔNIA}

A formação das cidades na Amazônia é importante compreender os contextos históricos e suas inserções nas diferentes temporalidades. Corrêa (1987), destaca a questão da urbanização concentrada na região, principalmente em relação as capitais da região. Além disso, a criação de novos núcleos vinculados às suas importâncias econômicas são os principais meios de transformação do modo de vida urbano na região.

Nesse contexto, baseado nessas transformações, Trindade Jr. (2013) destaca as tipologias de cidades na região: cidades-empresa, cidades rodoviárias e tradicionais, vinculadas as questões de inserção do capital, aos seus formatos de criação e padrões de ocupação. Além disso, a questão da "Urbanodiversidade" na Amazônia é vinculada as questões da presença "da Floresta" e "na Floresta", cuja questão de análise é voltada a inserção das mesmas ao contexto do capital e aos modos de vida vigente.

Nesses modos de vida vigente, é importante destacar a economia da região, baseada por muito tempo, nas concepções do extrativismo e em pouco tempo, passa a experimentar uma economia voltada a uma frente agropecuária, além da mineração ter ganhado peso em algumas regiões. Nesse processo, Trindade Jr. (2013, p.12), destaca a pressão exercida no meio ambiente, observando-se uma negação em relação ao já existente, ocasionando uma integração quase que existente com aquele cotidiano e vinculado a necessidade de atender aos circuitos globais.

Nesse contexto de atendimento aos circuitos globais, é importante entender inserção das cidades "na floresta" a partir da relação do estado com essa questão. Isso é destacado a partir de uma infraestrutura inicial e incentivos fiscais e econômicos, tanto a aspectos nacionais, quanto estrangeiros, tornando esse contexto um 


\section{Dispersão urbana e transporte público na Região Metropolitana de Belém: \\ Uma análise de Castanhal e Santa Izabel do Pará}

ponto de partida a inserção do país no mercado internacional, sobretudo as prerrogativas neoliberais, conforme analisa Trindade Jr. (2015, p.101).

Em relação a metropolização do espaço amazônico, as novas configurações estão vinculadas principalmente as duas maiores cidades da região: Manaus e Belém, que a partir dessa concepção de integração nacional, passaram a figurar com os principais destinos de fluxos e fixos da região. A primeira, em relação ao modelo Zona Franca e apresentando um aspecto metropolitano de uma concentração populacional apenas na sua área urbana, enquanto que Belém apresenta um processo totalmente diferenciado, vinculado a novas produções do espaço urbano.

Nesse contexto, é importante ressaltar Belém, como um dos vetores dos modais e políticas rodoviárias que surgiram com força a partir dos anos 1960. Nesse contexto, as áreas de expansão vinculadas principalmente aos municípios de Ananindeua e os que surgiram posteriormente, como Marituba, Santa Bárbara do Pará.

Esses novos espaços a surgir, conforme destaca Ribeiro (2018, p.139), podem ser confundidos como espaços periféricos, principalmente pela presença das classes mais baixas, algumas oriundas das baixadas de Belém e outras, como "cidade dormitório", assim vinculando a uma questão de migração pendular, válida também para os municípios de entorno metropolitano e das subcentralidades regionais, como é o caso de Castanhal e Santa Izabel do Pará.

Nessa construção acerca da região amazônica, os diversos conceitos relacionados ao espaço metropolitano e seu entorno, são vinculados a uma construção desenvolvimentista atual, mas também guardam traços vinculados a aspectos históricos, como no caso de Belém e Região Metropolitana, as concepções ferroviárias da Zona Bragantina, conforme descreve Leandro e Silva (2012), além das novas estruturações, vinculadas a um processo de cidade-região e também, das novas configurações pendulares e também, de fluxos e fixos vinculados ao formal e informal, a partir dos inúmeros circuitos existentes na metrópole.

\section{SISTEMAS DE TRANSPORTE, ORGANIZAÇÃO E TIPOLOGIAS EMPRESARIAIS}

Em relação ao ambiente metropolitano, entender a organização de um sistema de transporte, é vinculado de acordo com as necessidades e também o porte dos fluxos e fixos vigentes. Nessa concepção, o papel do estado é vinculado a uma atuação de organização e também, de assumir o papel do transporte coletivo como um vetor de desenvolvimento das cidades.

Ao longo da história, a questão da regulamentação econômica do transporte nas cidades, são vinculados principalmente a uma questão de padronização dos serviços e também, de mudanças técnicas e econômicas. Senna (2014), destaca nesse processo, a importância de soluções, sejam elas regionais ou urbanas, além do obedecer das instâncias administrativas vinculadas ao processo de planejamento, concessão 


\section{Dispersão urbana e transporte público na Região Metropolitana de Belém:}

Uma análise de Castanhal e Santa Izabel do Pará

e operação. Oliveira (2003, p.42), destaca nesse processo, as seguintes exigências: Generalidade, Eficiência, Modicidade, Cortesia e Continuidade, vinculados a um caráter essencial.

A organização do serviço de transporte é vinculada juntamente as instâncias administrativas, como um papel exclusivamente municipal. Devido aos possíveis sistemas metropolitanos, a questão passa a ser vinculada ao poder estadual. Senna (2014) e Rendeiro (2015), destaca nesse processo, as frentes de operação, baseadas em administração direta e processos de permissão e concessão, vinculando a relação estado $\mathrm{x}$ agente empresarial, como fornecedor do sistema de transporte, conforme visto abaixo.

Figura 01: Esquema envolvendo a relação estado x empresa

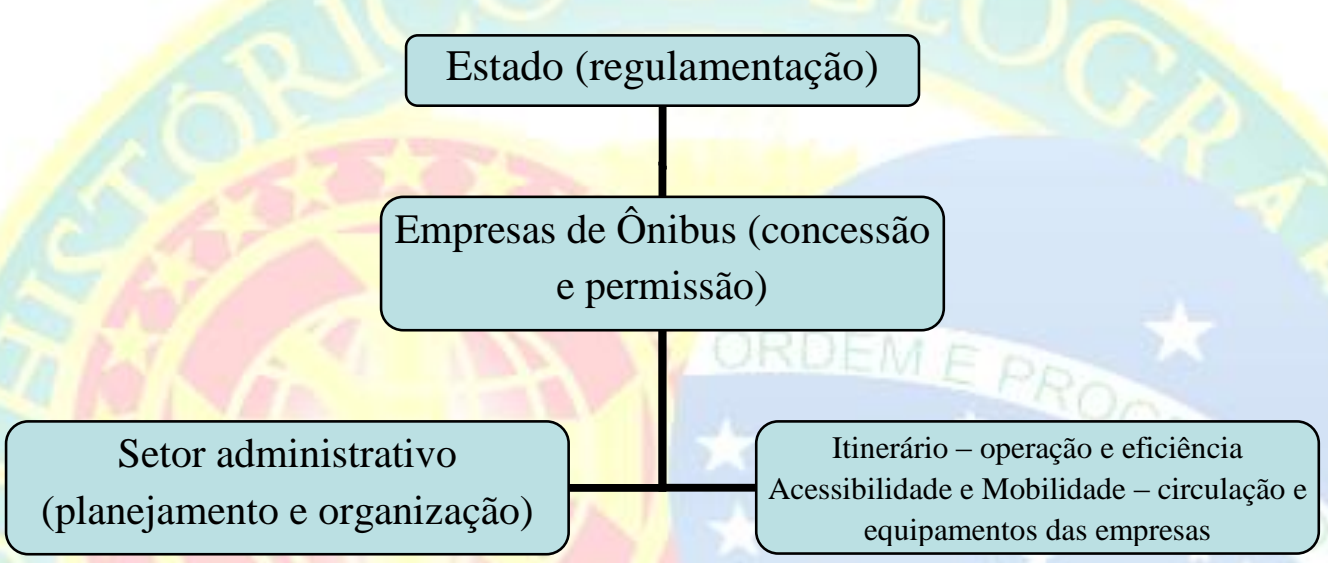

Elaborado por: Autores, 2020

A inserção dos grupos empresariais no sistema de transporte, tanto em monopólios, quando em oligopólios, é existente na questão dos circuitos superiores, como descreve Santos (2004b, p.139). Nesse contexto, a inserção é baseada principalmente em aspectos de burocracias e legislações vigentes, além da presença de monopólios estabelecidos, que favorecem esses últimos.

Na questão de monopólios e grupos empresariais, Henry (1999) e Castro (2015), destacam a existência de tipologias empresariais atuantes nas cidades, denominadas de Unidades de Produção do Serviço de transporte, divididas em 09 categorias: operadores individuais, unidades artesanais, auto viação familiar, empresas tradicionais, empresas evolutivas, empresas modernizantes, empresas hegemonizantes e empresas monopolizantes. Com isso, é relacionado a sua área de abrangência, sendo a primeira categoria vinculada a um alcance micro-local e a última vinculada a um alcance nacional.

Acerca da inserção no circuito da economia urbana, é destacado também as tipologias e abrangências empresariais, a vinculação aos seguintes tipos de sistema: convencional, vinculados a um aspecto de formalidade, regulação e eficiência ou posteriormente, aos circuitos inferiores, neste caso, os modais alternativos e complementares, que destaca Mamani (2004), que surgem a partir de uma necessidade de rapidez, mas vinculada ao atendimento as áreas em que os grandes grupos não exercem interesse, desencadeando o surgimento de novas tipologias empresariais e também, de tipos de linhas e serviços. 


\section{Dispersão urbana e transporte público na Região Metropolitana de Belém:}

Uma análise de Castanhal e Santa Izabel do Pará

A partir dessa concepção empresarial, a organização do sistema de transporte deverá estar vinculada as necessidades dos usuários e a uma regularidade de padrões, assim trazendo uma competência técnica e também, uma seguridade jurídica na atuação empresarial. Em diferentes regiões, essa construção empresarial está vinculada a interesses políticos e a inserção perante ao capital, tanto em necessidade de uma inserção local, quanto em uma inserção regional, vinculado aos processos metropolitanos.

\section{CONTEXTOS HISTÓRICOS DE CASTANHAL E SANTA IZABEL DO PARÁ}

Pensar sobre a organização urbana de Castanhal e Santa Izabel do Pará, é remeter a construção da Estrada de Ferro Belém - Bragança, inaugurada em 1884 e tendo um processo de importância para a Zona Bragantina. Isso é fomentado principalmente, a partir do período da Borracha, entre os anos de 1880 e 1890 , com a criação de núcleos de povoamento e de colonização estrangeira para trabalhar nas produções agrícolas, conforme destaca Leandro e Silva (2012).

O primeiro núcleo de povoamento nessa região criada, surgiram com o avanço das colônias da região correspondente ao atual município de Benevides, conforme descreve Cavalcante (2011, p.71), sendo esta criada ainda em meados de 1875, de onde estabeleceu Santa Izabel do Pará, com a primeira leva de imigrantes. Posteriormente, Castanhal passou a receber esse fluxo como parada de boiadeiros, recebendo a alcunha de Campos de Castanhal e surgindo como vila em 1899, conforme destaca Alves (2012, p.39).

A transformação em município de ambas as localidades, são datadas, respectivamente de 1932 e 1934, no governo do interventor Magalhães Barata. Nesse período, principalmente o núcleo de Santa Izabel, experimentou levas migratórias de japoneses, conforme destaca Cavalcante (2011, p.71).

Com a transformação dos modais ferroviários em rodoviários a partir dos anos 1960 e 1970 e as novas formas e estruturas, os processos de urbanização da região ganharam novas tonalidades. Santos (2004a), destaca que os movimentos de totalidade social, podem ocasionar as relações vigentes e surgindo novas funções.

Destacado esse processo, Cavalcante (2011) e Alves (2012), trazem em questão, as relações entre elas, mas ainda com um forte laço com a cidade de Belém. Além disso, Castanhal também é considerada uma centralidade da região bragantina e do nordeste paraense, sendo o principal polo de bens, serviços e comércio com as demais cidades da região.

Em um contexto atual, a cidade de Castanhal, conforme o IBGE (2019), estima cerca de 200.793 habitantes. Dentro do território pertencente a este, é destacada a Vila de Apeú, núcleo de povoamento também criado a partir da Belém-Bragança, hoje considerada como distrito, mas também é pautada como um dos bairros de Castanhal. Além dele, são contabilizados na área urbana de Castanhal cerca de 25 bairros e diversas comunidades rurais, destacando Macapazinho, Agrovila Iracema, Castelo Branco, Bacabal e Nazaré, conforme visto na figura abaixo. 
Dispersão urbana e transporte público na Região Metropolitana de Belém:

Uma análise de Castanhal e Santa Izabel do Pará

Figura 02: Bairros e principais comunidades de Castanhal

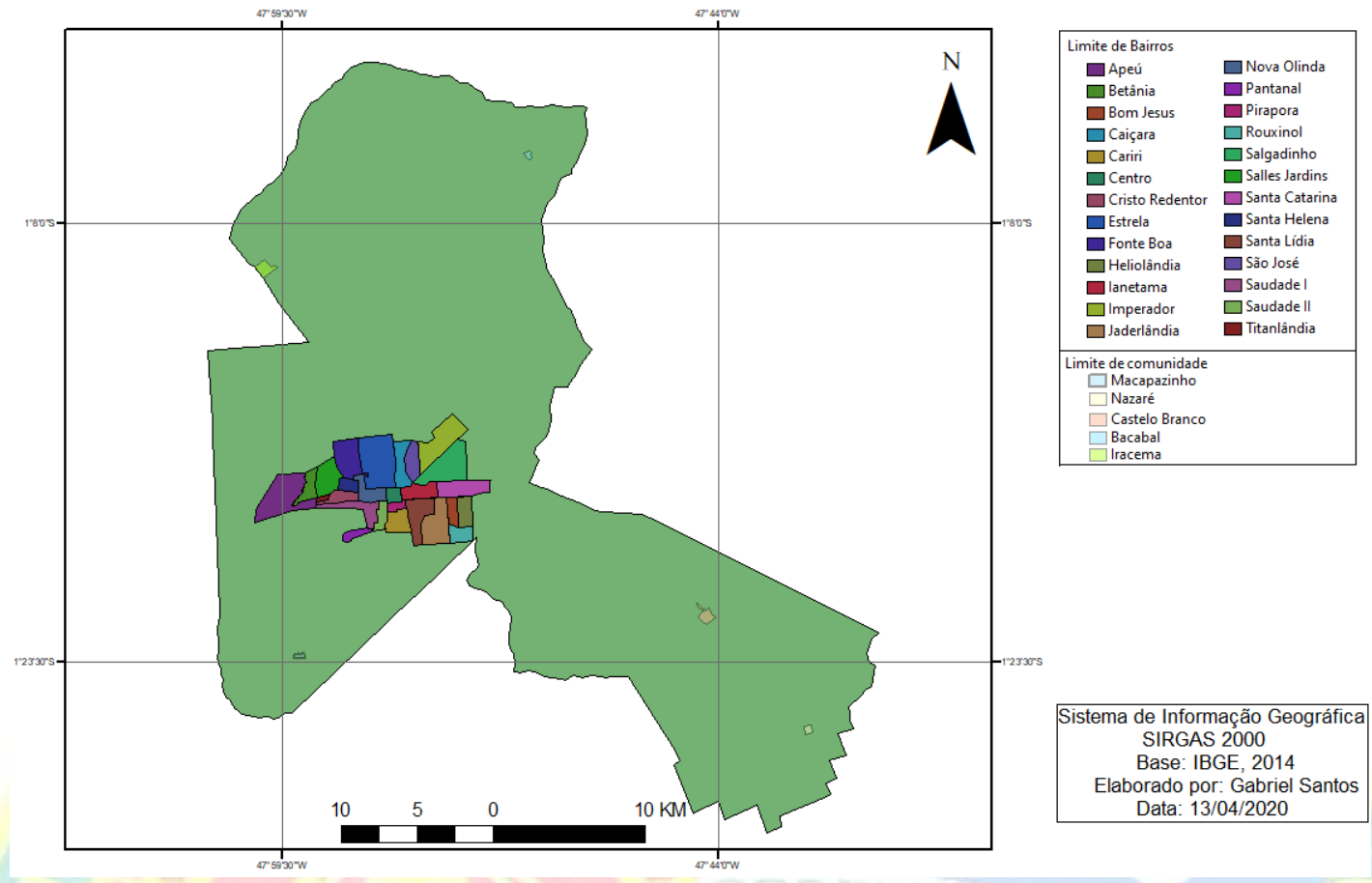

Já o município de Santa Izabel do Pará, em uma dinâmica populacional menor, concentra cerca de 70.801 habitantes (IBGE, 2019), concentrando 17 bairros e cerca de dois distritos: Americano e Caraparú e as Vilas de Conceição do Itá, Tacajós, Vila do Carmo e Trindade, conforme visto abaixo.

Figura 03: Bairros e principais comunidades de Santa Izabel do Pará

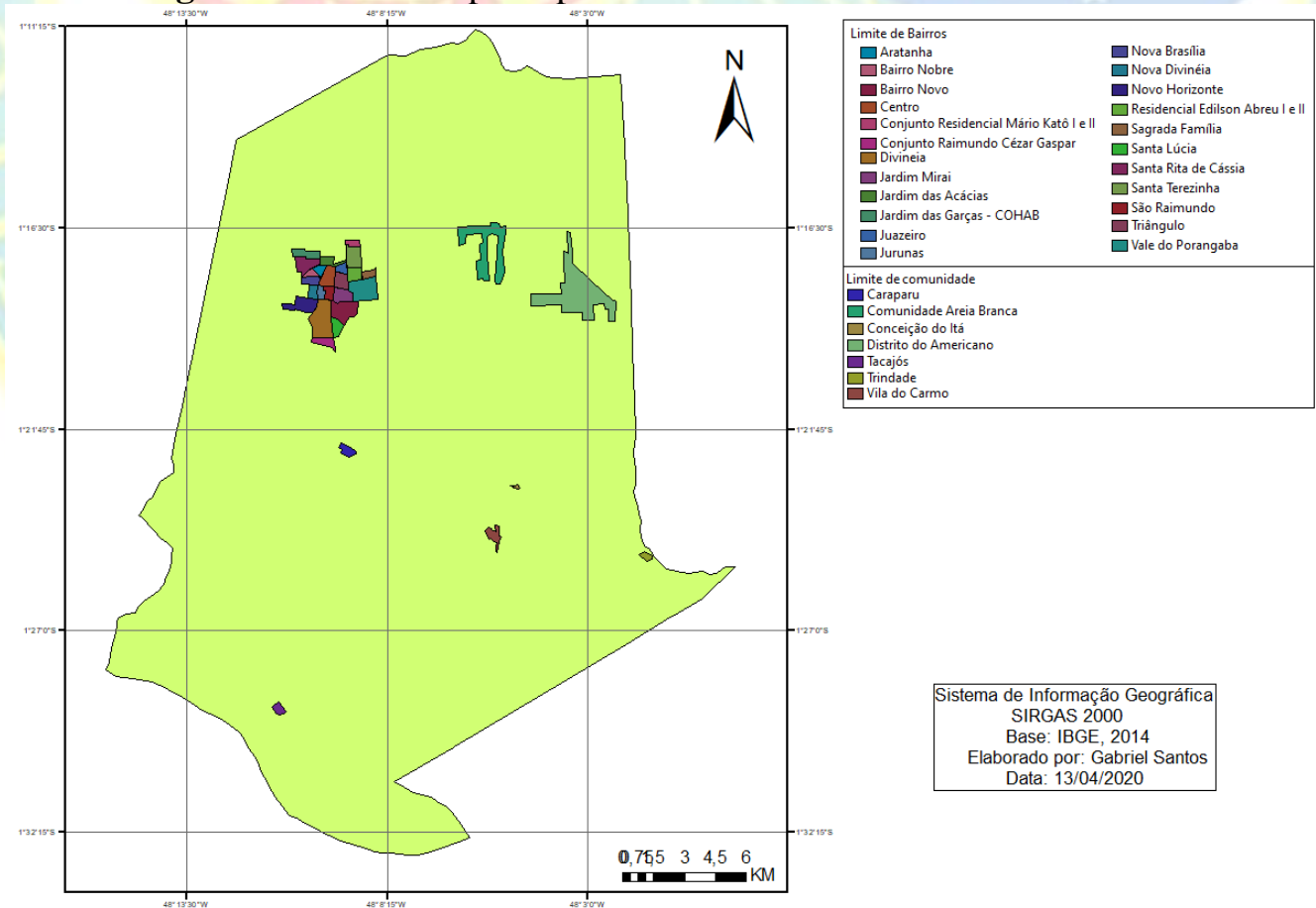

Elaborado por: Autores, 2020

Revista do Instituto Histórico e Geográfico do Pará (IHGP), (ISSN: 2359-0831 - on line), Belém, v. 08, n. 01, p. 54 78, jan.-jun. / 2021. 
A partir dessa configuração, é estabelecido as tipologias de organização no transporte, baseada nas ações dos poderes públicos, mas também da informalidade em algumas áreas específicas. Com isso, surgem diversas tipologias e configurações acerca do sistema de transporte nas áreas em questão.

\section{TIPOLOGIAS DE EMPRESAS E LINHAS}

As configurações empresariais no transporte coletivo de Castanhal e Santa Izabel do Pará, são relacionadas em alguns aspectos, com empresas hegemonizantes e monopolizantes, conforme descrevem Henry (1999) e Castro (2015, p.41-42). Além disso, existem em uma escala menor, a presença de operadores individuais, neste caso, podemos destacar, as cooperativas ou permissionários individuais, dependendo das áreas de operação.

No âmbito de regulação de linhas com destino entre esses municípios e a cidade de Belém, destaca o papel da ARCON (Agência de Regulação e Controle de Serviços Públicos do Estado do Pará), nas linhas intermunicipais (estas com destino Rodoviária x Rodoviária) ou semiurbanas/suburbanas (Rodoviária $\mathrm{x}$ Rodoviária com paradas ao longo do trajeto), além das tipologias de serviço. No estado, o órgão regulamenta os seguintes tipos de serviço:

Quadro 01 - Tipologia de linhas Rodoviárias existentes na Região Metropolitana de Belém

\begin{tabular}{|l|l|l|l|}
\hline \multicolumn{1}{|c|}{ SERVIÇO } & \multicolumn{1}{|c|}{ DEFINIÇÃO } & \multicolumn{1}{|c|}{ DISTÂNCIA } & \multicolumn{1}{|c|}{ VEÍCULO } \\
\hline Alternativo & $\begin{array}{l}\text { Linhas definidas a partir da definição } \\
\text { total de serviço existente de } \\
\text { complementar e convencional }\end{array}$ & $\begin{array}{l}\text { Linhas com até 250 } \\
\text { quilômetros }\end{array}$ & $\begin{array}{l}\text { Baixa Capacidade } \\
\text { (micro-ônibus e } \\
\text { vans) }\end{array}$ \\
\hline Complementar & $\begin{array}{l}\text { Ligação inexistente ou deficiente das } \\
\text { linhas convencionais no estado do Pará }\end{array}$ & $\begin{array}{l}\text { Linhas de curta e e } \\
\text { média distância }\end{array}$ & $\begin{array}{l}\text { Baixa Capacidade } \\
\text { (micro-ônibus) }\end{array}$ \\
\hline Convencional & $\begin{array}{l}\text { Serviço definido por operação em } \\
\text { áreas, terminais e locais definidos a } \\
\text { partir da quilometragem e também, } \\
\text { operação exclusiva dentro do estado do } \\
\text { Pará. }\end{array}$ & $\begin{array}{l}\text { Médio Percurso: até } \\
\text { 250 quilômetros } \\
\text { Longo Percurso: acima } \\
\text { de 250 quilômetros }\end{array}$ & $\begin{array}{l}\text { Baixa, Média e } \\
\text { Alta Capacidade } \\
\text { (motorização ou } \\
\text { traseira ou } \\
\text { dianteira } \\
\text { depende do } \\
\text { percurso, Double } \\
\text { Decker) }\end{array}$ \\
\hline
\end{tabular}

Elaborado por: Autores (2020), com base em ARCON (2010 e 2017)

Acerca dos sistemas municipais, são apresentadas as seguintes tipologias e suas funções dentro dos sistemas convencionais ou complementares de transporte. Com isso, as tipologias são abrangentes as áreas urbanas ou rurais, além das funções de fluxos e fixos nos municípios em questão

Quadro 02 - Tipologia de linhas Rodoviárias nos municípios de Castanhal e Santa Izabel do Pará

\begin{tabular}{|c|l|}
\hline TIPOLOGIA & \multicolumn{1}{|c|}{ FUNÇÃO } \\
\hline Radial & $\begin{array}{l}\text { Origem bairro } \mathrm{x} \text { centro } \mathrm{x} \text { bairro, tendo enfoque principal na ligação com as áreas } \\
\text { centrais }\end{array}$ \\
\hline Circular & $\begin{array}{l}\text { Ligação entre várias regiões da cidade, podendo adentrar ou não a região central da } \\
\text { cidade. }\end{array}$ \\
\hline
\end{tabular}




\begin{tabular}{|c|l|}
\hline Interbairros & $\begin{array}{l}\text { Passando por duas regiões ou polos geradores de viagem, sem integrar com a região } \\
\text { central. }\end{array}$ \\
\hline Rurais/Distritais & $\begin{array}{l}\text { Linhas originárias de vilas, distritos ou ramais fora do perímetro urbano, com } \\
\text { destino as áreas centrais ou feiras municipais, operadas em formado de cooperativas } \\
\text { ou permissionários individuais. }\end{array}$ \\
\hline
\end{tabular}

Elaborado por: Autores (2020), com base em Ferraz e Torres (2001)

As redes de transporte coletivo das cidades, a partir das funções e tipologias de linhas, contribuem também para a formação de locais e polos voltados ao comércio, devido ao fluxo de bens e serviços. Por isso, a necessidade de um planejamento adequado, é de suma importância ao contexto organizacional e da eficiência operacional das empresas e permissionários do sistema de transporte.

\section{O PENDULAR E O TRANSPORTE METROPOLITANO DE PASSAGEIROS NOS MUNICÍPIOS EM QUESTÃO}

Apesar do pertencimento das cidades na Região Metropolitana, o processo de criação e regulação das linhas não é concentradas nas mãos da Superintendência de Mobilidade Urbana de Belém (SeMOB), diferente dos demais municípios. Portanto, são controladas pela ARCON e enquadradas como semiurbanas. Segundo Borges (2006), essa tipologia é caracterizada por um serviço prestado em áreas urbanas contíguas, com características operacionais típicas de transporte urbano, além de transpor os limites das áreas urbanas, metropolitanas ou aglomerações urbanas.

Nestes casos, é interessante entender as distâncias entre ambos e em relação a Belém. Em primeiro momento, Santa Izabel e Castanhal, utilizando o transporte público, é um trajeto de aproximadamente 15 minutos (figura 04), a partir da utilização do transporte público. Com isso, conforme destaca Cavalcante (2011), a utilização dos serviços essenciais em Castanhal é mais abrangente que na capital paraense.

Figura 04: Ônibus em Rota - Santa Izabel x Castanhal

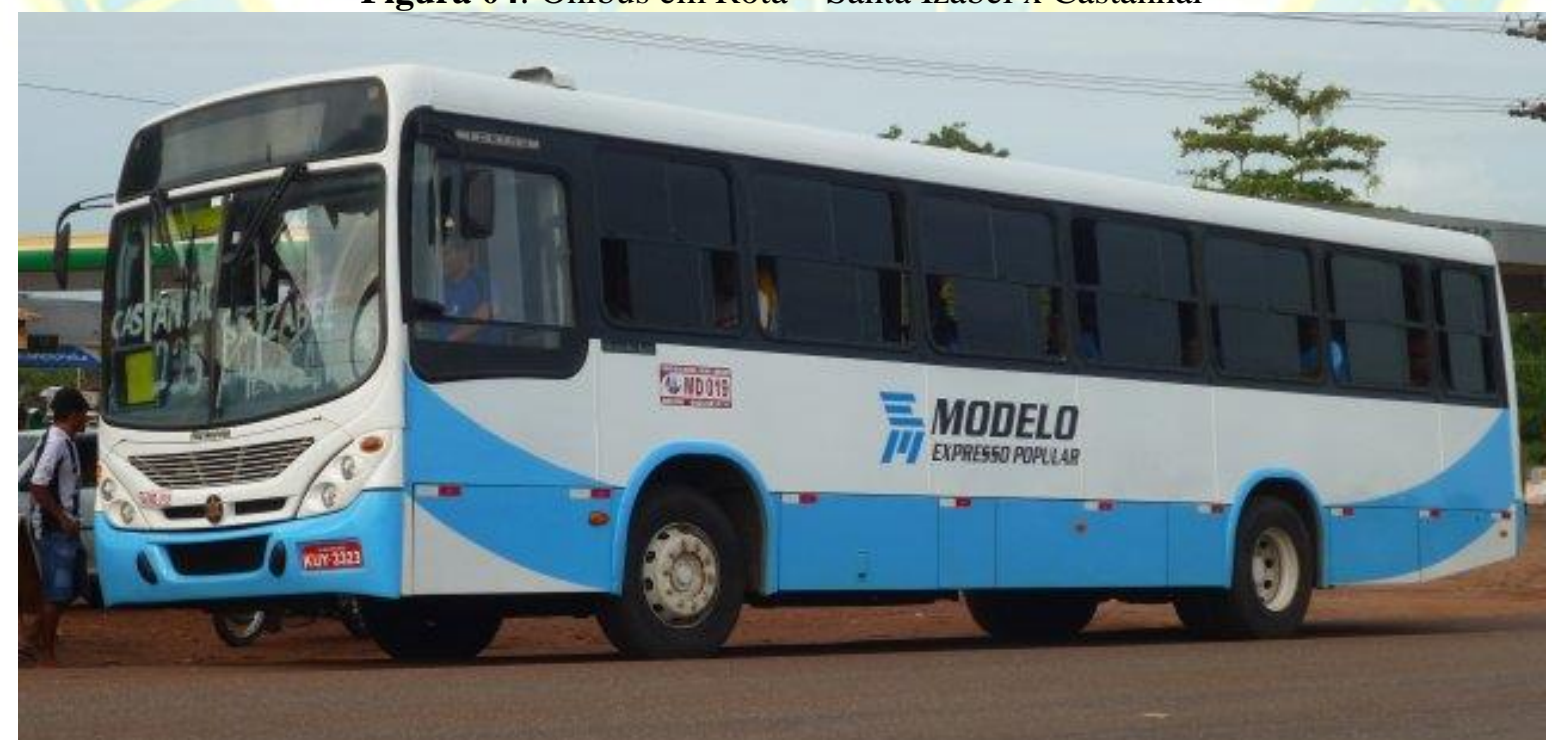

Créditos: Acervo de Diego Miranda 
Outro aspecto a ser analisado também são as tipologias de veículos e tarifas aplicadas, que são regulamentadas pela ARCON-PA, a partir das concessões e permissões aplicadas ao transporte de passageiros nestes dois municípios. Abaixo, a quadro que mostra os valores tarifários e as tipologias utilizadas no transporte de passageiros em relação a estes municípios.

Quadro 03 - Valores das Tarifas Intermunicipais, com base no ano de 2019

\begin{tabular}{|c|c|c|c|}
\hline ROTA/VIA & EMPRESA & TARIFA & TIPO DE VEÍCULO \\
\hline Belém x Santa Izabel do Pará & $\begin{array}{l}\text { Expresso Modelo e } \\
\text { Rota Expresso }\end{array}$ & $\mathrm{R} \$ 8,15$ & \multirow{4}{*}{$\begin{array}{l}\text { Ônibus Padrão Rodoviário com } \\
\text { motorização dianteira e Ônibus } \\
\text { Padrão Urbano }\end{array}$} \\
\hline Belém x Castanhal & $\begin{array}{l}\text { Expresso Modelo e } \\
\text { Rota Expresso }\end{array}$ & $\begin{array}{l}\mathrm{A}-\mathrm{R} \$ \\
12,37^{*} \\
\mathrm{~B}-\mathrm{R} \$ \\
15,86^{*}\end{array}$ & \\
\hline $\begin{array}{l}\text { Belém x Santa Izabel do Pará } \\
\text { (Tacajós e Porto de Minas) }\end{array}$ & Expresso Modelo & $\mathrm{R} \$ 18,22$ & \\
\hline $\begin{array}{l}\text { Belém x Santa Izabel do Pará } \\
\text { (Vila do Americano) }\end{array}$ & Expresso Modelo & $\mathrm{R} \$ 9,66$ & \\
\hline $\begin{array}{l}\text { Santa Izabel x Castanhal (via } \\
\text { Vila do Americano) }\end{array}$ & $\begin{array}{l}\text { Expresso Modelo } \\
\text { (ModCast e ModSat) }\end{array}$ & $\begin{array}{l}\mathrm{A}-\mathrm{R} \$ \\
5,36^{*} \\
\mathrm{~B}-\mathrm{R} \$ \\
6,91^{*}\end{array}$ & Ônibus Padrão Urbano \\
\hline
\end{tabular}

*Tarifa A - poderá passageiros em pé; Tarifa $\mathrm{B}$ - somente passageiros sentados

Elaborado por: Autores (2020), com base em ARCON (2019)

Nos dois primeiros trajetos citados, eles cruzam todo o eixo viário da BR-316, passando pelos municípios de Benevides, Marituba e Ananindeua, tendo em alguns casos, tarifas mais baratas ou promocionais como forma de atração de passageiros para os destinos e também se diferenciam pelos formatos veiculares, já citados, conforme figura 05 . 


\section{Dispersão urbana e transporte público na Região Metropolitana de Belém:}

Uma análise de Castanhal e Santa Izabel do Pará

Figura 05: Percurso das linhas em relação a Belém

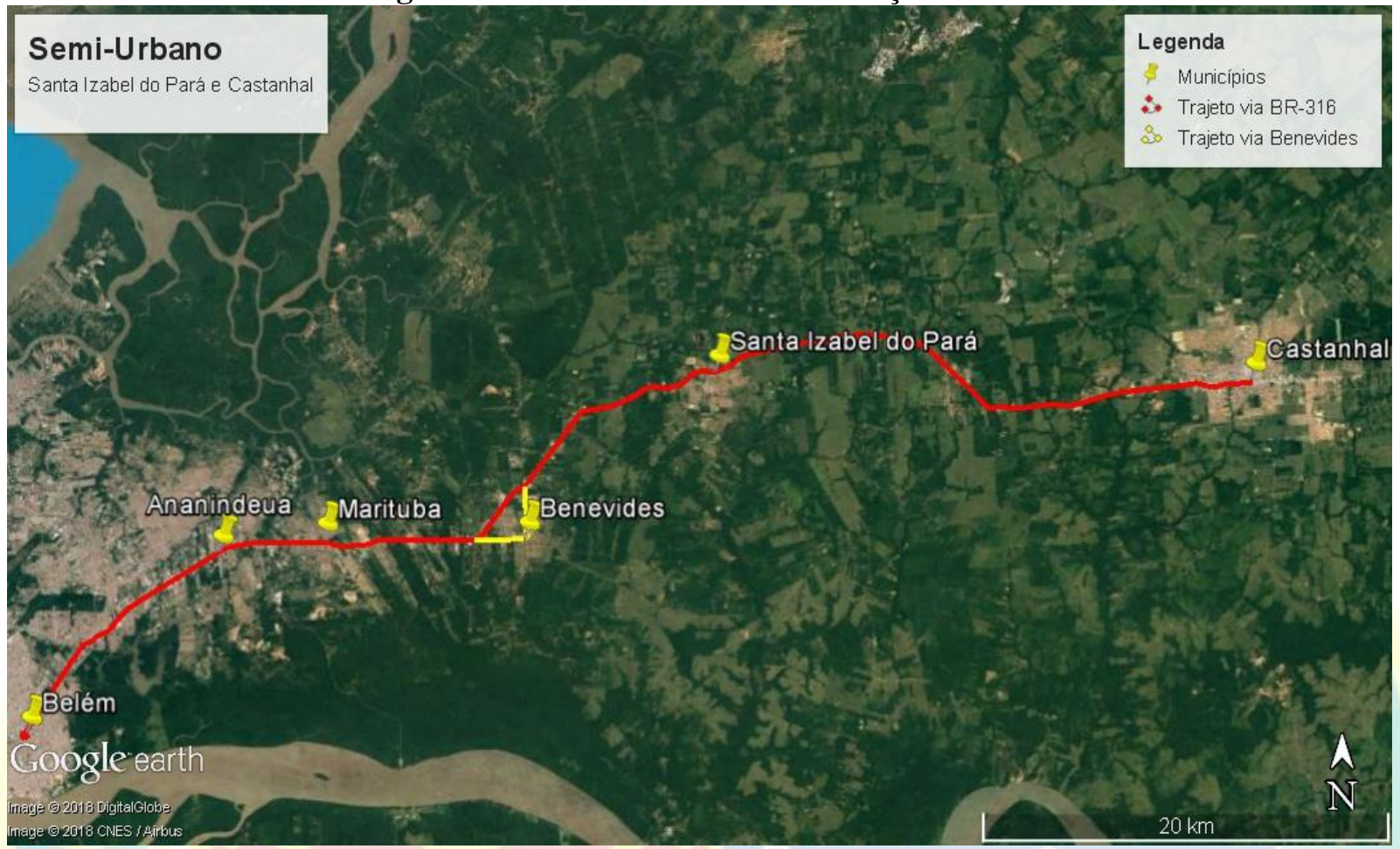

Elaborado por: Autores, 2020

Nota-se nos trajetos, a presença promocional em alguns trechos (neste caso, o trecho via Benevides), afim de tornar a operação mais forte, principalmente para afastar a presença do complementar ou individual, presente nas rotas. Com isso, nota-se uma presença dos circuitos inferiores da economia, em que Santos (2004b) define como polos de atividades com pouco capital, neste caso, podendo ser pouco atrativa aos agentes empresariais.

Nos trajetos em questão, é importante destacar principalmente, a hegemonia e também, o papel monopolizante do serviço de transporte intermunicipal para os destinos citados. Anteriormente, a razão Expresso Modelo, se dividiu em duas: ModCast, referente ao município de Castanhal e ModSat, relacionados ao município de Santa Izabel do Pará, sendo a configuração atual, conforme registro, relacionadas ao primeiro nome, como percebido abaixo.

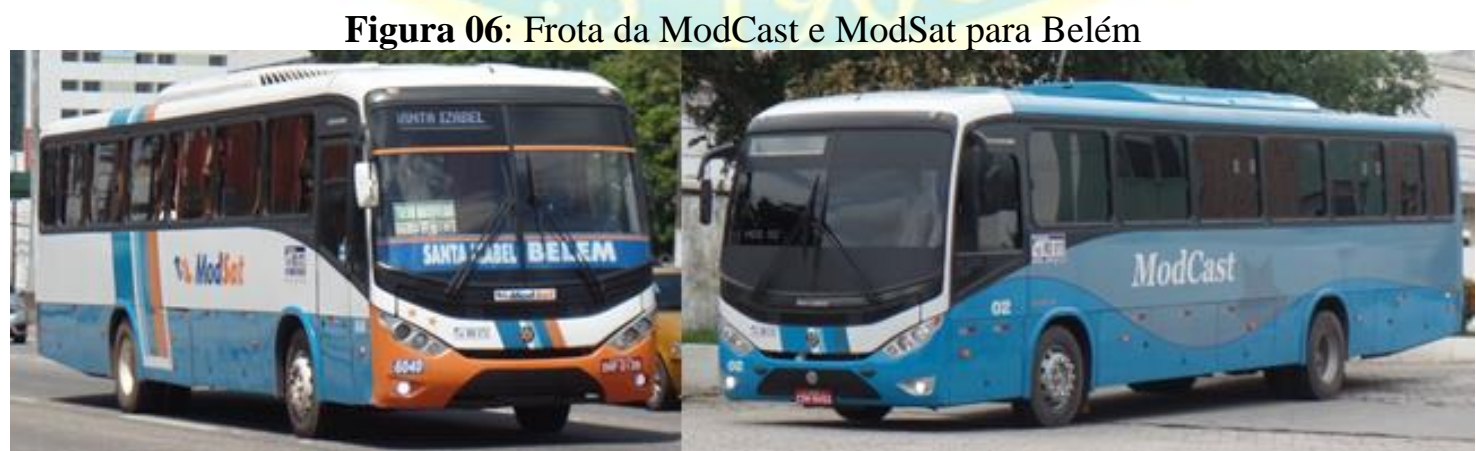

Créditos: Acervo de Thiago Moreira dos Santos 
Salim Filho (2007) e Silva (2010), destacam essa noção de circuito inferior presente como concorrente ao formal, como algo relacionado a crítica ao modelo de desenvolvimento da Região Metropolitana de Belém. Com isso, percebe-se o processo de organização da economia e também, do espaço urbano em questão, exercendo ou o papel de sub-centralidade metropolitana ou uma outra centralidade sub-regional, como Castanhal exerce perante o Nordeste Paraense, a partir das disparidades, conforme analisa Ribeiro (2015).

A necessidade de uma organização no serviço de transporte, frente a questão da expansão urbana, contribuiu para o fortalecimento dos sistemas alternativos e complementares, ainda em meados dos anos 1990. Segundo Salim Filho (2007), os fatores exigidos eram alinhados a uma organização jurídica, culminando no surgimento de cooperativas e empresas a explorar o serviço, sob a determinação da ARCON, neste caso, vinculando esta operação intermunicipal a um órgão estadual, principalmente pela inserção dos municípios na Região Metropolitana, conforme destaca Rendeiro (2015).

As vantagens apresentadas no serviço, principalmente a partir dos anos 2000 , foram as questões em relação a horários e a possíveis questões do deslocamento em relação as rodoviárias dessas cidades. Isto era causado, principalmente pelos próprios permissionários buscarem seus passageiros em casa, já economizando no deslocamento para as rodoviárias.

A regulamentação desse serviço é feita juntamente também com as secretarias municipais de transporte e a ARCON, devido às mesmas ultrapassar os perímetros urbanos. Segundo Silva (2010), a criação dos primeiros organismos de cooperativas, também foram favorecidos, devido a excessos de lotação nas empresas grandes regulamentadas e o coibir do transporte clandestino, neste caso, destacando os prós e contras em cada tipologia de serviço, conforme visto na tabela abaixo.

Quadro 04 - Tipologia de linhas Rodoviárias existentes nos municípios de Castanhal e Santa Izabel do Pará

\begin{tabular}{|c|c|c|}
\hline SIGLA & RAZÃO SOCIAL/NOME FANTASIA & LINHA OPERANTE \\
\hline ATAC & $\begin{array}{l}\text { Associação de Transporte Alternativo de } \\
\text { Castanhal }\end{array}$ & Belém x Castanhal \\
\hline SINPROVAN & $\begin{array}{l}\text { Sindicato dos Proprietários de Vans e Micro- } \\
\text { Ônibus Autorizados no Transporte Alternativo } \\
\text { do Pará }\end{array}$ & $\begin{array}{l}\text { Belém x Castanhal } \\
\text { Belém x Santa Izabel do Pará }\end{array}$ \\
\hline COTASI & $\begin{array}{l}\text { Cooperativa de Transportes Autônomos } \\
\text { Izabelense }\end{array}$ & Belém x Santa Izabel do Pará \\
\hline COOPERSATI & Cooperativa de Transportes de Santa Izabel & Belém x Santa Izabel do Pará \\
\hline COONTESPA & $\begin{array}{l}\text { Cooperativa de Transportes Rodoviários de } \\
\text { Passageiros }\end{array}$ & Belém x Santa Izabel do Pará \\
\hline
\end{tabular}

Elaborado por: Autores (2020), com base em Silva (2010) e ARCON (2018) 


\section{Dispersão urbana e transporte público na Região Metropolitana de Belém: \\ Uma análise de Castanhal e Santa Izabel do Pará}

Um dos aspectos relacionados ao transporte alternativo, é em relação as gratuidades em vigor. Segundo Cavalcante (2011), o transporte alternativo acaba por não respeitar, em muitos aspectos, a tarifa destinada a estudantes, cobrando apenas o valor integral, ao contrário das empresas formais que operam as linhas, que são passíveis de punição.

Diferentemente do transporte formal, os veículos a serem utilizados nesse tipo de transporte, são de capacidade até 20 lugares, no qual entram as padronizações de adesivo e identificação por parte dos órgãos regulamentadores. Além disso, diferem-se também em estruturas, visto que em muitos casos, não dispõe de terminais adequados, montando as suas operações em alguns locais, considerados insalubres ou precários, conforme figura abaixo.

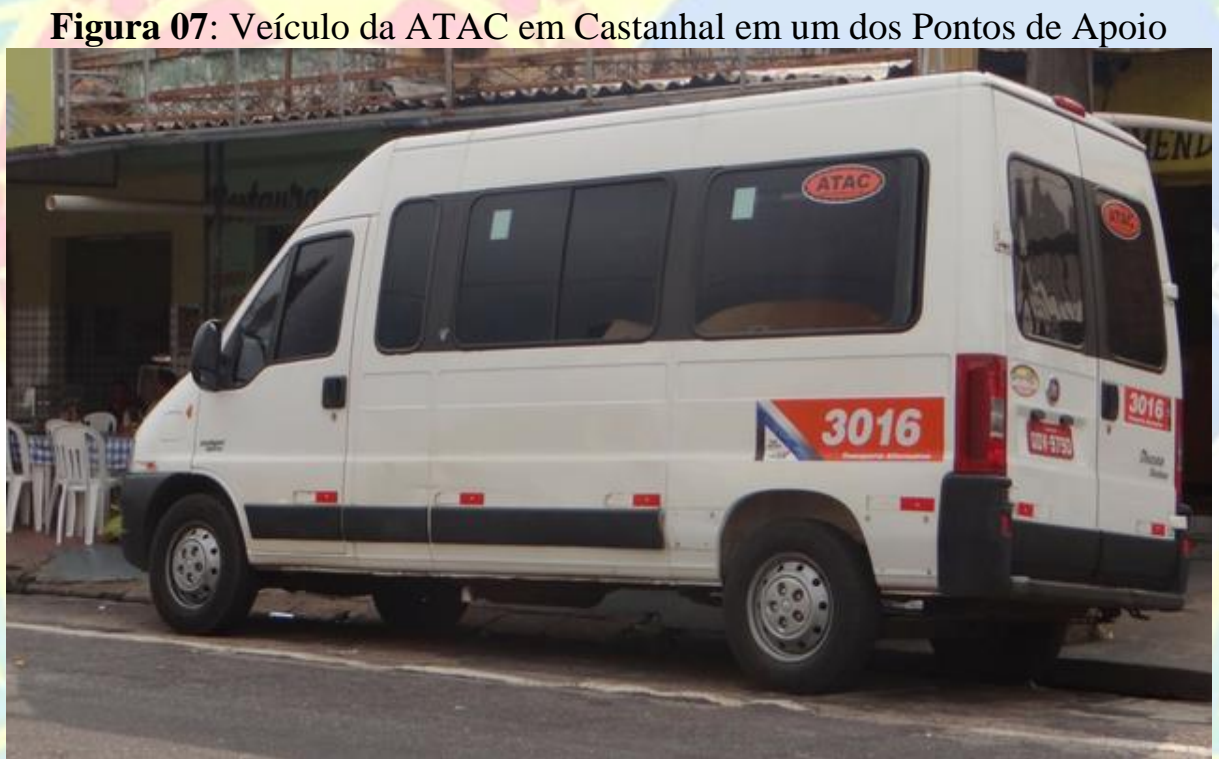

Crédito: Guia de Castanhal

Com isso, nota-se a utilização do transporte alternativo semiurbano nesses municípios, segundo Silva (2010) e Cavalcante (2011), para o usufruto dos serviços básicos. Destacam-se os polos de atendimento em Castanhal, para quem é advindo de Santa Izabel ou para Belém, em aspectos mais complexos, sobretudo envolvendo a questão de educação e saúde.

Nesse aspecto, a questão "marginal", englobando o Sistema de Transporte Complementar e Alternativo, ganha novas configurações com o processo de regulamentação. Silva (2010, p.17), destaca nesse processo, que apesar dessa transformação, esse modal de transporte ainda é visto como um complicador, devido ao desenvolvimento diferenciado das grandes empresas. 


\section{CENTRALIDADE SUB-REGIONAL E PERTENCIMENTO AO ESPAÇO METROPOLITANO - COTIDIANOS DO TRANSPORTE DE PASSAGEIROS EM CASTANHAL}

Os fluxos e fixos existentes entre os municípios de Castanhal e Santa Izabel, são vinculadas principalmente em relação ao transporte rodoviário, na dependência de serviços e também no processo de metropolização dispersa na região. A questão do uso e ocupação do solo na região, é debatida por Cavalcante (2011, p.106), é destacado principalmente pelas classes mais baixas, para que haja uma apropriação de um solo mais barato. Em consequência disso, o distanciamento dos núcleos metropolitanos torna-se cada vez mais iminente.

As mudanças na malha viária, é resultante por dois aspectos: ocupações irregulares e também os projetos recentes de habitação. Neste contexto, destaca-se o Programa Minha Casa Minha Vida (PMCMV), conforme destacam Cavalcante (2011), Cruz (2019) e Santos (2019), que alteram diretamente os fluxos de transporte nas cidades, causando também as questões envolvendo fluxos e a relação de origem x destino.

É importante nesse contexto, destacar nos serviços de transporte, as questões do formal e informal, principalmente relacionadas aos interesses do capital e de seus agentes nas operações. A partir disso, a presença dos circuitos superiores e inferiores, influenciam diretamente na construção do espaço, em que Alves (2019) e Cavalcante (2019), destacam nesse aspecto, os novos arranjos espaciais, tanto em relação com as ocupações, quanto com os fluxos, vistos em abrangência urbana ou rural.

Pelo seu porte populacional e econômico, o município de Castanhal contém uma organização acerca do Sistema de Transporte. O Sistema de Transporte Municipal de Castanhal é administrado pela Secretaria Municipal de Trânsito e Transportes (SEMUTRAN), em que o modelo adotado é previsto em ordens de serviço, prática comum nas empresas e sistemas municipais da Região Metropolitana de Belém.

Atualmente, o sistema de Castanhal é composto por cerca de 19 linhas urbanas e divididas em 09 empresas, totalizando uma frota de 78 veículos, em uma tarifa de $\mathrm{R} \$ 2,70$ e transportando diariamente cerca de 30 mil pessoas, conforme descrito abaixo.

\section{Quadro 05 - Linhas Urbanas de Castanhal}

\begin{tabular}{|c|c|c|}
\hline LINHA & ITINERÁRIO & EMPRESA \\
\hline 001 & KM-07 x FCAT (Parque dos Castanhais) & Expresso São José \\
\hline 003 & Jardim Tokio x Centro & Mayara Transportes \\
\hline 003 & Parque dos Castanhais x FCAT & Expresso São José \\
\hline 004 & Parque dos Buritis x FCAT & Luane Transportes \\
\hline 005 & Fonte Boa x UFPA & Cidade Nova \\
\hline 007 & Cariri x Centro & Expresso Macapazinho Amorim Vitória \\
\hline 008 & Imperador x Centro & \\
\hline
\end{tabular}


Dispersão urbana e transporte público na Região Metropolitana de Belém:

Uma análise de Castanhal e Santa Izabel do Pará

\begin{tabular}{|c|c|c|}
\hline 009 & Jaderlândia x Cohab $\left(2^{\text {a }}\right.$ Rua $)$ & Rosas Transportes \\
\hline 010 & Pantanal x Centro (Milagre) & Expresso Macapazinho \\
\hline 011 & Milagre x FCAT & Expresso Macapazinho \\
\hline 013 & Betânia x Centro (Apeú) & Salve Maria \\
\hline 014 & Jagatá x UFPA & Luane Transportes \\
\hline 015 & Propira x Centro (Campos Elíseos) & Mayara Transportes \\
\hline 017 & Fonte Boa x UFPA (Barão) & Cidade Nova \\
\hline 020 & Calúcia x Centro (Jardim das Acácias) & Expresso Macapazinho \\
\hline 024 & Santa Helena x Centro (Jardim Modelo) & Mayara Transportes \\
\hline 029 & Ipês x Jardim Tangará & Ruth Transportes \\
\hline 033 & Santa Terezinha x Centro (Pacuquara/Apeú) & Cidade Nova \\
\hline 046 & Jaderlândia (Conjunto Roxinol) x Apeú $-3^{a}$ Rua & Salve Maria \\
\hline
\end{tabular}

Elaborado por: Autores (2020), com base de pesquisa de Campo realizada em 2018 e Sales e Vale (2016)

As disputas por passageiros nas linhas citadas são concentradas em alguns locais estratégicos, tratando assim, a questão dos Polos Geradores de Viagem (PGV), destacando a Faculdade de Castanhal (FCAT), a Universidade Federal do Pará (UFPA) e o Centro Comercial. Santos (2019, p.74), destaca nesse processo, a adaptação desses itinerários, que antes seguia um padrão Radial, com destino ao Centro da Cidade, passando por outros locais, como o Instituto Federal do Pará (IFPA), as Unidades de Pronto Atendimento e também, as faculdades particulares que estão surgindo no município.

Figura 08: Coletivos com destino a UFPA e área Central na cidade de Castanhal

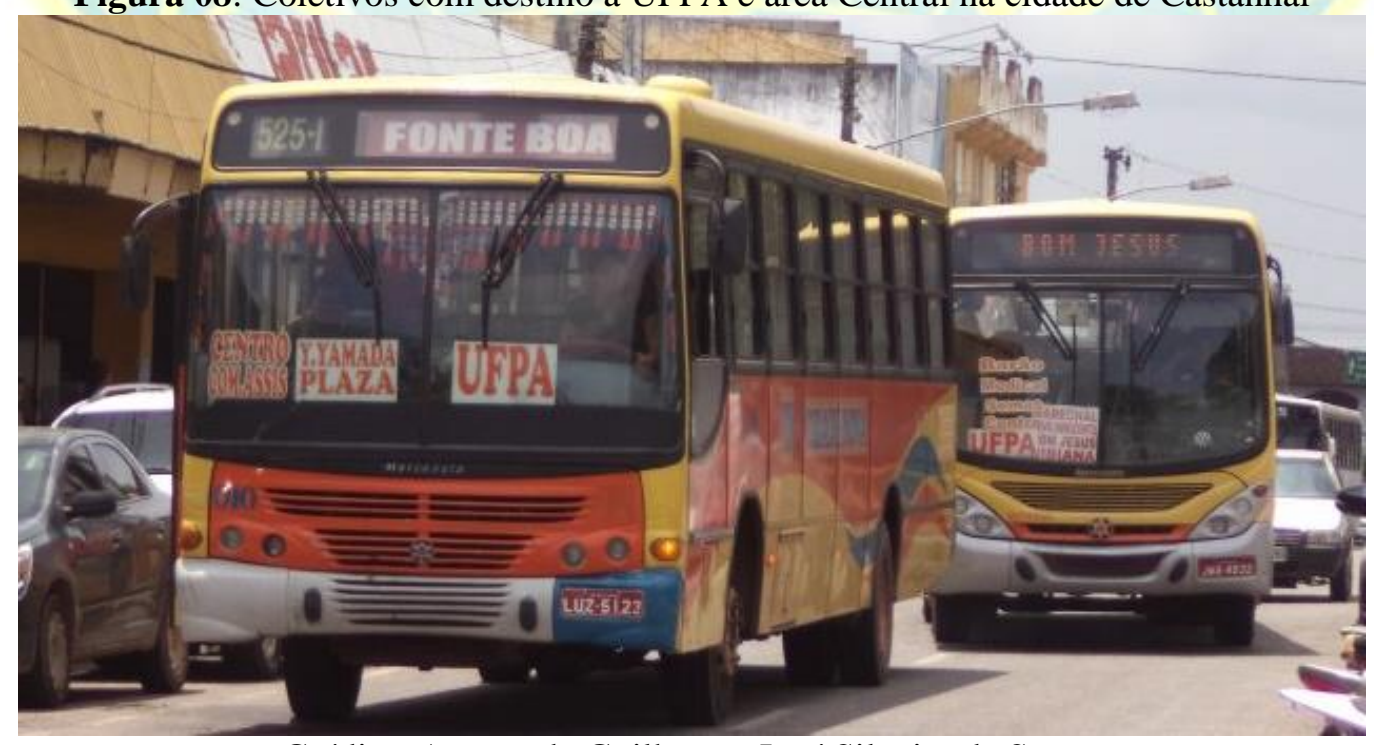

Crédito: Acervo de Guilherme José Silveira de Souza 


\section{Dispersão urbana e transporte público na Região Metropolitana de Belém: \\ Uma análise de Castanhal e Santa Izabel do Pará}

Acerca dos destinos, em relação as origens de itinerários, acabam por contribuir com a territorialização dos bairros em que são destinados a operação, prática corrente no serviço de transporte. Nesse aspecto, podese notar o monopólio das operações em áreas específicas, podendo haver em alguns pontos, sobreposição, ou carência do serviço de transporte nos bairros, conforme visto no mapa abaixo.

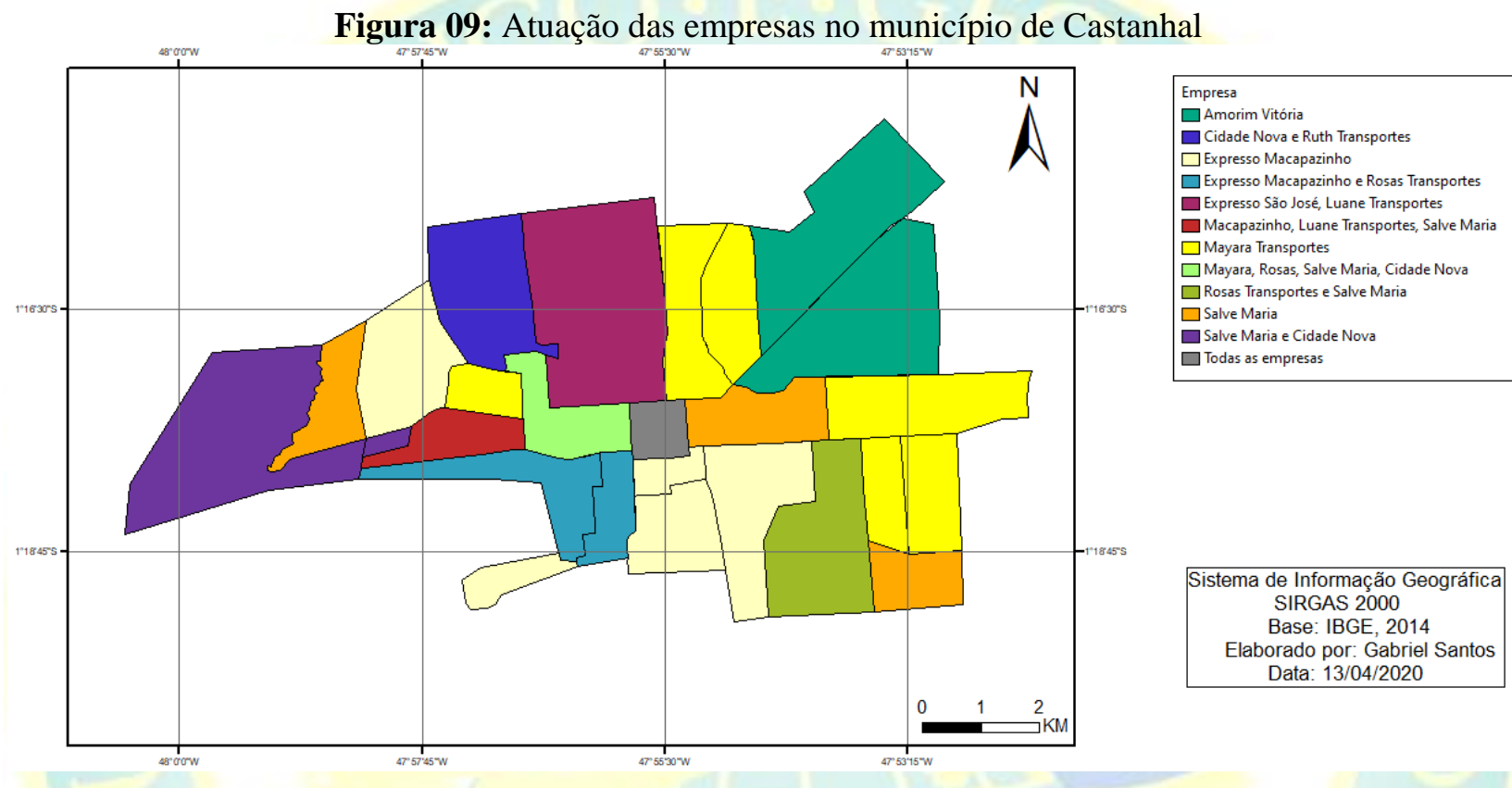

Nota-se nesse processo de expansão urbana da cidade de Castanhal, sobretudo relacionado a dispersão da metrópole Belém. Alves (2012) ressalta a importância da iniciativa privada voltada a construção civil como principal fomentador do padrão de dispersão, vinculada a aspectos da capital paraense. Destacam-se Cruz (2019) e Santos (2019), a atual especulação imobiliária, tanto em aspecto privado, pelo fomento a esses empreendimentos, quanto pelo Minha Casa Minha Vida, equipamentos estruturados e também, aos assentamentos precários que surgem na cidade.

Em relação ao deslocamento dos passageiros, percebe-se também as demandas a cruzar a BR-316, presente em todo o trecho urbano do município. Silva (2010), destaca que o trecho no município, assim como em Belém e nos demais municípios da Região Metropolitana, são relacionadas com as demandas estaduais e municipais da rodovia, ocasionando as problemáticas de trafegabilidade, principalmente aos Polos Geradores de Viagem existentes, além mesmo da presença maciça do transporte de outras localidades que param no município de Castanhal.

Outra percepção envolvendo os agentes empresariais no município de Castanhal, é em relação aos aspectos econômicos. Alves (2012), destaca as diferentes relações empresariais e sociais no âmbito de transportes, tanto nos circuitos superiores, quanto nos circuitos inferiores da economia. No caso dos operadores do transporte coletivo de Castanhal, é perceptível, a presença de um empresariado local, 


\section{Dispersão urbana e transporte público na Região Metropolitana de Belém: \\ Uma análise de Castanhal e Santa Izabel do Pará}

registrado também como ME (Microempresa) ou LTDA (sociedade limitada, baseada em cotas divididas entre os sócios, conforme destacam Sales e Vale (2016, p.29).

O transporte com destino a área rural do município (comunidades, assentamentos), é fomentado a partir das seguintes conjunturas: deslocamento de pessoas das áreas rurais para os centros urbanos, a partir da necessidade de serviços e também, pelo transporte de cargas ao longo do percurso. A concepção e organização desse sistema, ao longo dos anos, conforme analisa Lopes (2019, p.69), é relacionado principalmente a falta de regulamentação acerca do formato operacional, principalmente relacionado aos veículos que operam nesse tipo de serviço.

Nesse quesito, as tipologias existentes variam, conforme analisa Henry (1999), de operadores individuais ou empresas artesanais. A concepção desses agentes empresariais, são baseadas em atendimentos periféricos, serviços de fretamento, atendimento a clientes individuais não atendidos pela oferta vigente e principalmente, pela ausência total do poder público como referente.

No âmbito de Castanhal, o serviço para algumas localidades, neste caso, distritos e vilas localizadas em rodovias estaduais, tem respaldo da ARCON. Nessa questão, o circuito superior da economia, dos grandes agentes empresarias, acabam por contar com itinerários definidos de atendimento e tarifas de acordo com o tipo de veículo e lotação de passageiros, conforme visto abaixo.

Quadro 06 - Linhas da ARCON na região de Castanhal

\begin{tabular}{|c|c|c|}
\hline ITINERÁRIO & EMPRESA & TARIFA \\
\hline Castanhal x Americano (via Apeú) & Expresso Modelo & $\mathrm{R} \$ 3,24$ \\
\hline Castanhal x Americano (via Transapeú) & Expresso São Francisco* & $\mathrm{R} \$ 3,53$ \\
\hline
\end{tabular}

*Já conteve vinculação com a Expresso Modelo

Elaborado por: Autores (2020), com base em ARCON (2019)

Nesse aspecto organizacional, destaca-se a atuação da Expresso Modelo, já presente nas linhas com destino a Belém e ao município de Santa Izabel do Pará. A partir disso, a empresa consegue consolidar as operações. Diferente dela, a Expresso São Francisco, considerada até pouco tempo uma das subsidiárias da mesma, guarda uma operação em menor escala, conforme visto na figura abaixo.

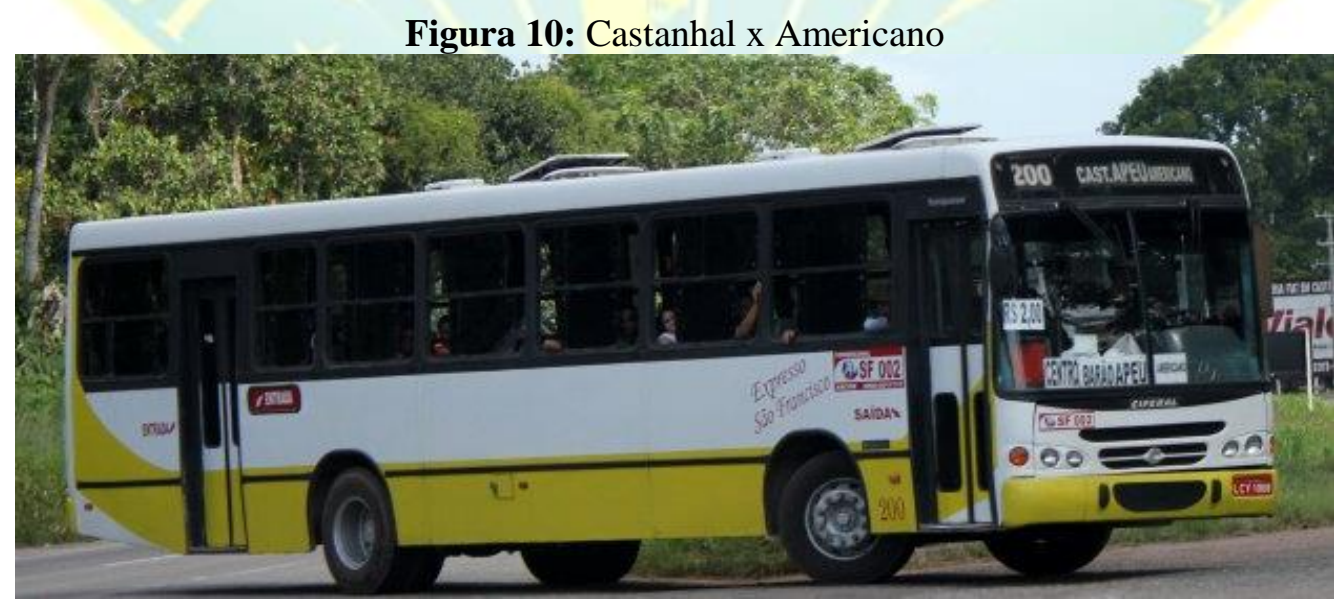

Crédito: Acervo de Tarcísio Schneider

Revista do Instituto Histórico e Geográfico do Pará (IHGP), (ISSN: 2359-0831 - on line), Belém, v. 08, n. 01, p. 54 78, jan.-jun. / 2021. 
Para as demais localidades, a presença de permissionários individuais ou pequenas empresas, é a predominância operacional desse sistema. Nesse contexto, é importante ressaltar a presença de poucos veículos, adaptações necessárias aos trajetos, como relacionados a frota, destacado por Castro et al (2018, p.179) e Lopes (2019, p.65), tanto na inserção de veículos, quanto na questão mecânica dos mesmos, para melhor adaptação aos trajetos existente nas regiões que esse serviço atende.

A configuração de transporte para entre essas localidades rurais e o município de Castanhal, é entendida principalmente como escoamento da produção, destacada por Guilherme Junior (2013, p.76), como forma de vender as mercadorias nas feiras e demais locais do município de Castanhal. Nesse circuito inferior ou até mesmo, informal, os impactos visíveis da operação se estendem para os destinos e áreas de desembarque de passageiros na cidade (figura 11).

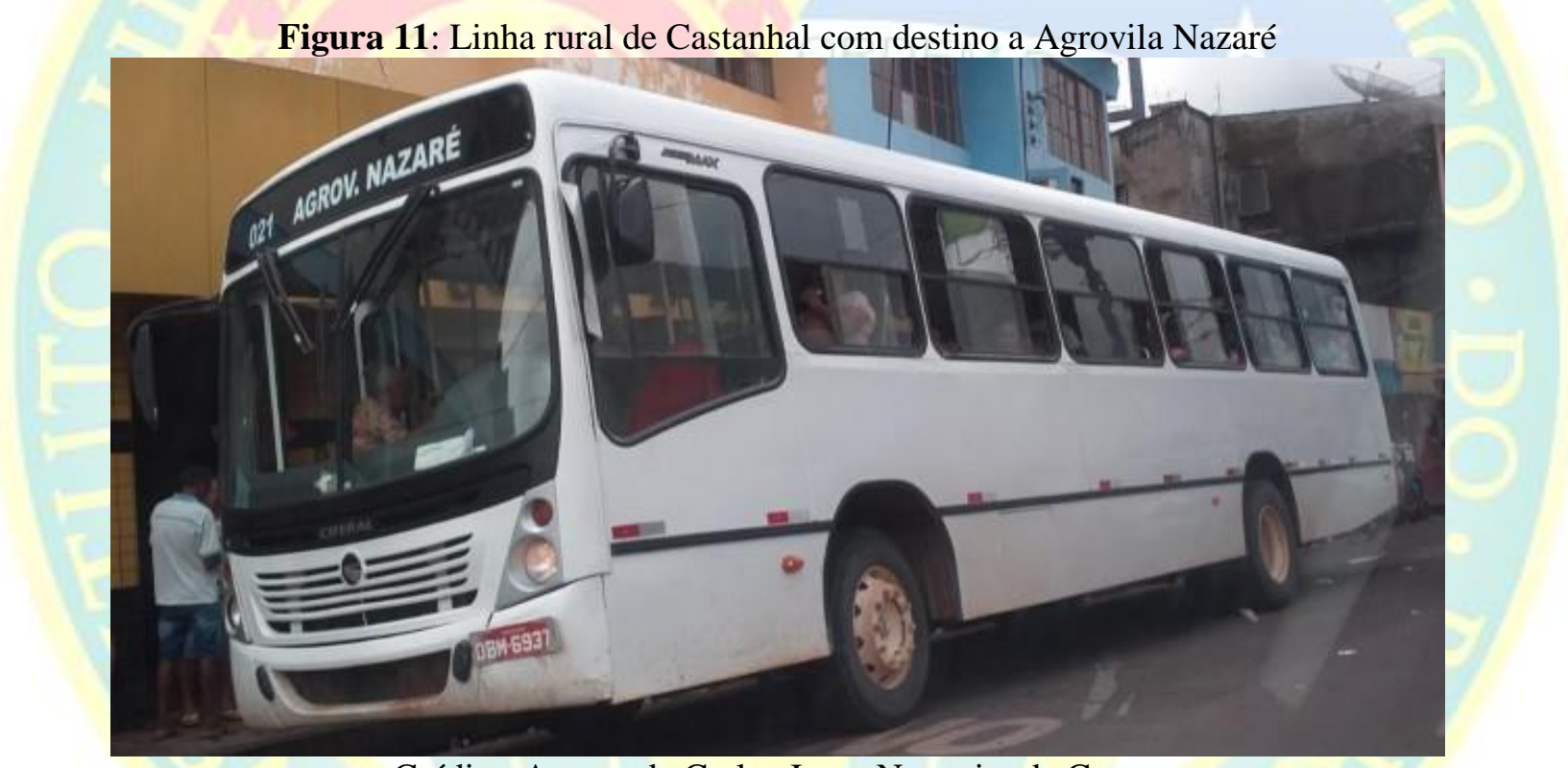

Crédito: Acervo de Carlos Jorge Nogueira de Castro

Abaixo, a configuração operacional das linhas rurais e seus permissionários ou operadores do circuito.

\begin{tabular}{|c|c|} 
Quadro 07 - Linhas e permissionários rurais na região de Castanhal \\
\hline ITINERÁRIO/VIA & EMPRESA \\
\hline Castanhal x Macapazinho & TransMacapazinho \\
\hline Castanhal x Agrovila Iracema (Santa Terezinha, Vila Conceição) & TransIracema \\
\hline Castanhal x Castelo Branco & Permissionários Individuais \\
\hline Castanhal x Bacabal & Permissionários Individuais \\
\hline Castanhal x Nazaré & Permissionários Individuais \\
\hline Castanhal x Assentamento João Paulo II & Permissionários Individuais \\
\hline Castanhal x Vila de Pernambuco (Trindade)* & Permissionários Individuais \\
\hline
\end{tabular}

*Localidade pertencente ao município de Inhangapi, mas com proximidade de Santa Izabel do Pará.

Elaborado por: Autores, 2020, com base em Lopes (2019). 
Nota-se também nesse contexto, a atuação de permissionários frente a algumas vilas localizadas entre os limites entre municípios. Tanto no aspecto formal, quanto informal, a presença de algumas áreas pertencentes ao município de Inhangapi, localizada na região do entorno ou, em alguns casos, da Região Ampliada de Belém. Carmo et al (2015), destaca o processo de migração pendular para os municípios da Região, principalmente relacionadas ao trabalho e também ao consumo de bens e serviços, tanto em Castanhal e Santa Izabel, quanto nos demais municípios integrantes.

\section{PRECARIZAÇÃO URBANA E SOBREVIVÊNCIA NO RURAL - O COTIDIANO DE SANTA IZABEL DO PARÁ}

Em contrapartida de Castanhal, o município de Santa Izabel do Pará atualmente não dispõe de um serviço urbano regular. Até meados de 2014, conforme relatos de moradores da cidade, o serviço de transporte era realizado de forma precarizada e contava com poucos ônibus que realizavam o serviço circular por todo o município, mas que foram descontinuados. No que se constava em registros, a precariedade da frota era iminente, além da falta da eficiência do sistema, perceptível na figura abaixo.

Figura 12: Circular Santa Izabel em operação em 2014

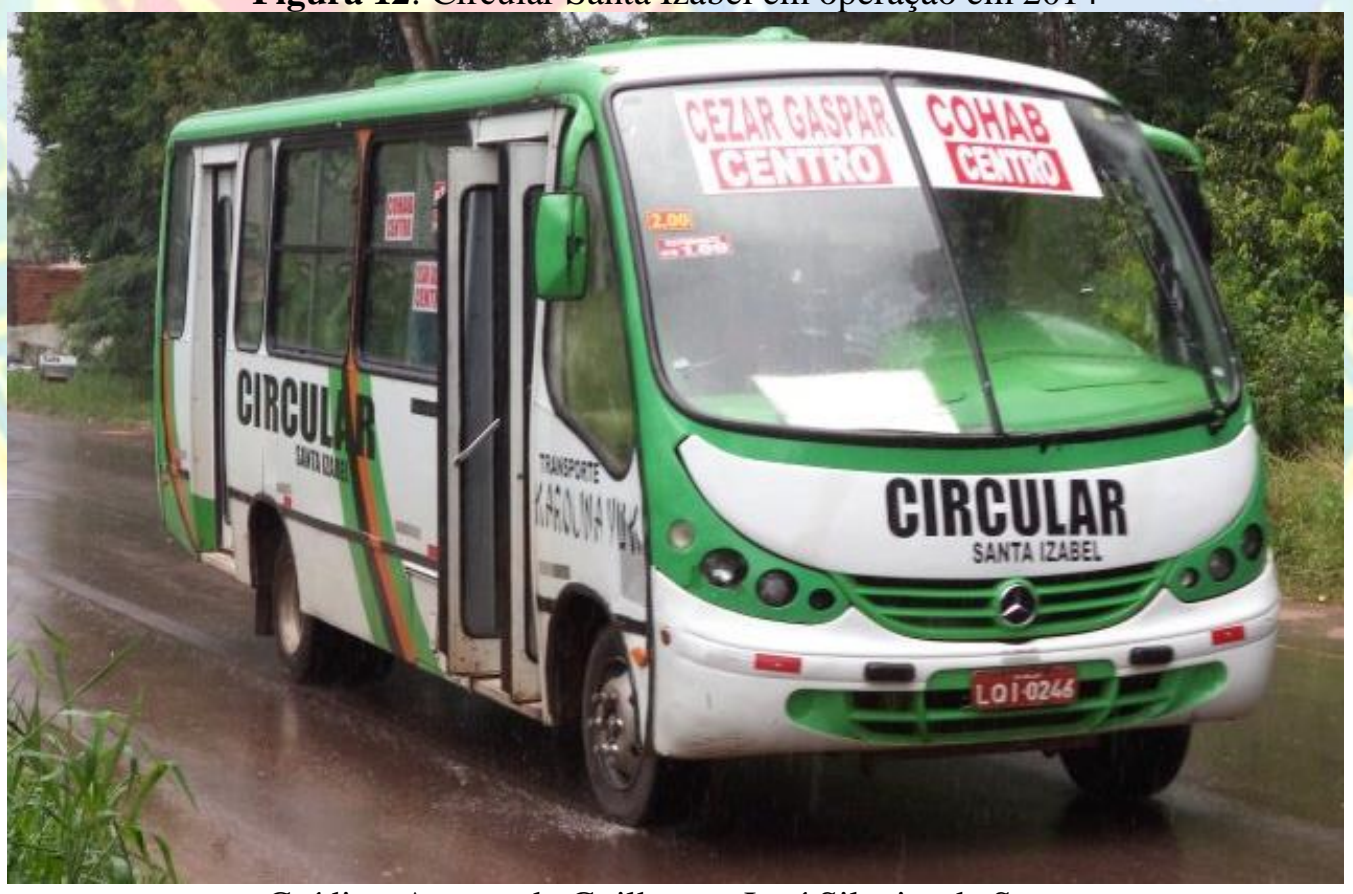

Crédito: Acervo de Guilherme José Silveira de Souza

Atualmente, a região vem sendo atendida principalmente por táxis e pelo serviço informal, posteriormente regulamentado, dos mototaxis, presentes em grande parte das cidades médias da região Amazônica e também estudada em maiores proporções em Castanhal, a partir das análises de Salim Filho (2007), mas predominante com maior intensidade em Santa Izabel, devido a inexistência de um sistema de transporte propriamente dito. 
No caso de Santa Izabel, devido a essa deficiência, a questão do garantir o cumprimento das normativas é relacionada em compartilhamento, entre o município com os mototaxistas e a ARCON, a qual responde pelo transporte semiurbano no estado do Pará. Cavalcante (2011, p.149), destaca nessa conjuntura, a relação centro-periferia que o município exerce com Belém, principalmente pela facilidade no modal de linhas intermunicipais/semiurbanas, em que Souza (2015), destaca a garantia no planejamento dos órgãos fiscalizadores perante essa excepcionalidade.

A partir dessa conjuntura, os circuitos informais da economia, exerce um grande papel de interesse, tanto em aspecto do serviço de mototaxi, predominante no município, quanto nos deslocamentos para as vilas e comunidades existentes fora do perímetro urbano. Isso contribui para uma rede de transportes considerada precarizada, mas necessária perante o contexto de expansão, além de mudanças nos usos e formatos de ocupação do solo na região.

Apesar da precarização da operação urbana, a operação no transporte rural e distrital é maior, apesar das poucas áreas atendidas pelas linhas provenientes de Castanhal e a atuação dupla das empresas Expresso Modelo, caracterizada pela hegemonia já destacada no outro município, conforme visto agora.

Quadro 08 - Linhas da ARCON cadastradas no município de Santa Izabel do Pará

\begin{tabular}{|l|l|c|}
\hline \multicolumn{1}{|c|}{ ITINERÁRIO } & \multicolumn{1}{|c|}{ EMPRESA } & TARIFA \\
\hline Santa Izabel x Porto da Balsa* & Expresso Modelo, Liliel Transportes & $\mathrm{R} \$ 6,18$ \\
\hline Santa Izabel x Americano & Expresso Modelo & $\mathrm{R} \$ 3,24$ \\
\hline
\end{tabular}

*Localidade pertencente ao município de Inhangapi, mas com proximidade de Santa Izabel do Pará. Elaborado por: Autores (2020), com base em ARCON (2019)

Em relação as linhas com permissionários ou empresas do circuito inferior, é destaque as localidades que contém atrativos turísticos, como balneários eventos religiosos na região. Monteiro (2003, p. 52), destaca a variável das estâncias balneárias, como uma clientela vinculada ao baixo custo e uma diferenciação social. Abaixo, a operação do sistema a partir das necessidades e inserções desse circuito na organização do espaço.

Quadro 10: Linhas rurais informais de Santa Izabel do Pará

\begin{tabular}{|c|c|c|}
\hline ITINERÁRIO & EMPRESA & TARIFA \\
\hline Pernambuco x Santa Izabel (via Vila do Carmo)* & Transfé & \multirow{6}{*}{$\begin{array}{l}\text { Valor } \\
\text { Desconhecido }\end{array}$} \\
\hline Santa Izabel x Apeú & Permissionários Individuais & \\
\hline Santa Izabel x Conceição do Itá & Permissionários Individuais & \\
\hline Santa Izabel x Caraparu & Permissionários Individuais & \\
\hline Santa Izabel x Tacajós & Permissionários Individuais & \\
\hline Santa Izabel x Ferreira Pena & Permissionários Individuais & \\
\hline
\end{tabular}

*Localidade pertencente ao município de Inhangapi, mas com proximidade de Santa Izabel do Pará.

Elaborado por: Autores (2020), com base em Pesquisa de Campo realizada em 2018. 


\section{Dispersão urbana e transporte público na Região Metropolitana de Belém:}

Uma análise de Castanhal e Santa Izabel do Pará

A construção do Sistema Rural e Distrital ao longo dos anos nessa região, é acompanhada dos fatores envolvendo principalmente a relação campo x cidade e suas peculiaridades. Além disso, Silva (2010, p.31), destaca nesse processo, a inserção das camadas mais baixas, a partir de uma permeabilidade disponível no sistema capitalista. Nessa configuração, Bezerra (2009), acaba por destacar também a necessidade do escoamento de produção dessas áreas, tornando o sistema rural de transporte uma via de fluxos de pessoas em um aspecto de pendular, mas servindo de importância ao escoamento da produção.

\section{CONSIDERAÇÕES FINAIS}

A inserção recente dos municípios de Castanhal e Santa Izabel do Pará no cenário da Região Metropolitana de Belém, em um contexto mais recente, contribuiu para novas organizações acerca do espaço e de seu uso. Além disso, nota-se também, a inserção desses municípios frente a periferização do espaço em muitos aspectos, principalmente no que tange ao distanciamento dos grandes centros.

O serviço de transporte de passageiros, é considerado como um dos parâmetros de desenvolvimento e também das necessidades do ir e vir dessas populações. A partir disso, entra o papel dos circuitos superiores e inferiores, além da necessidade de delimitação e estruturação do poder público, partindo de um princípio de eficiência e operacionalização dos sistemas de transporte.

A nova conjuntura das cidades em questão, representam uma dispersão frente a metrópole belenense, na qual a partir das relações de dependência, acabam por construir também uma rede própria, vinculada a uma sub-centralidade metropolitana. No contexto de Castanhal, além dessa relação com Belém, o destaque é válido para a construção identitária com o Nordeste Paraense e a região Bragantina, aliada aos contextos históricos e também econômicos.

Com isso, a estruturação do transporte perante a dispersão e novas centralidades se tornam fator essencial para a reprodução de capital. Além disso, a eficiência e operacionalização do sistema de transporte, também é vista como uma forma a acompanhar os diversos circuitos presentes na metropolização e dispersão desse espaço em transformação.

\section{AGRADECIMENTOS}

Agradecimentos ao Conselho Nacional de Desenvolvimento Científico e Tecnológico e a Fundação de Amparo à Pesquisa do Estado do Amazonas pelo fomento da pesquisa entre os anos de 2017 a 2019.

\section{REFERÊNCIAS}

AGÊNCIA REGULADORA DE SERVIÇOS PÚBLICOS DO PARÁ. Disciplina a outorga de autorização para o serviço alternativo de transporte rodoviário intermunicipal de passageiros de médio percurso e dá outras providências. Disponível em: http://www.arcon.pa.gov.br/sites/default/files/resolucao_arcon_no_05_1999__alternativo_atualizada_junho_2017_0.pdf - Acesso em: 11/04/2020. 
AGÊNCIA REGULADORA DE SERVIÇOS PÚBLICOS DO PARÁ. Disciplina a outorga de autorização para o serviço complementar de transporte rodoviário intermunicipal de passageiros e dá outras providências. Disponível em: http://www.arcon.pa.gov.br/sites/default/files/resolucao_arcon_no_15_2010complement.pdf - Acesso em: 11/04/2020

AGÊNCIA REGULADORA DE SERVIÇOS PÚBLICOS DO PARÁ. Disciplina a outorga de autorização para o serviço convencional de transporte rodoviário intermunicipal de passageiros de médio e longo percurso e dá outras providências. Disponível em: http://www.arcon.pa.gov.br/sites/default/files/resolucao_arcon_no_01_2000__convencional_atualizado_junho_2017_0.pdf - Acesso em: 11/04/2020

AGÊNCIA REGULADORA DE SERVIÇOS PÚBLICOS DO PARÁ. Tabela de Tarifas Rodoviárias. Disponível

http://www.arcon.pa.gov.br/sites/default/files/tabela_de_tarifas_rodo_reaj_460_nov18_a_out19.pdf - Acesso em: 11/04/2020.

ALVES, Cyntia Santos Daltro. Formas espaciais recentes da urbanização na Amazônia: a dinâmica socioespacial do município de Castanhal em face do processo de dispersão metropolitana de Belém. 2012. 150 f. Dissertação (Mestrado em Geografia) - Universidade Federal do Pará - Programa de PósGraduação em Geografia, Belém.

ALVES, Cyntia Santos Daltro. Formas espaciais recentes da urbanização na Amazônia: a dinâmica socioespacial do município de Castanhal. In: TRINDADE JUNIOR, Saint-Clair Cordeiro; SANTOS, Tiago Veloso (Orgs.). O urbano e metropolitano em Belém: (Re)configurações sócioespaciais e estratégias de planejamento e gestão. $1^{\mathrm{a} e d . R i o ~ d e ~ J a n e i r o: ~ C o n s e q u e ̂ n c i a, ~ 2019, ~ v . ~ 1, ~ p . ~ 17-40 . ~}$

AMARAL, Márcio Douglas Brito; RIBEIRO, Willame de Oliveira. Castanhal (PA): Entre a Dinâmica Metropolitana e a Centralidade Sub-Regional de uma Cidade Média. PRACS: Revista Eletrônica de Humanidades do Curso de Ciências Sociais da UNIFAP, v. 9, p. 77-105, 2016.

BEZERRA, Francisco de Assis Pinto. Crescimento da produção da mandioca e os impactos econômicos no nordeste paraense: o caso do Distrito de Americano no Município de Santa Izabel do Pará. 2009, 199f. Dissertação (Mestrado em Planejamento do Desenvolvimento) - Universidade Federal do Pará, Núcleo de Altos Estudos Amazônicos, Programa de Pós-Graduação em Desenvolvimento Sustentável do Trópico Úmido.

BORGES, Rodrigo César Neiva. Definição de Transporte Coletivo Urbano. Nota Técnica: Câmara dos Deputados. Disponível em: http://bd.camara.gov.br/bd/bitstream/handle/bdcamara/1720/definicao_transporte_borges.pdf

CARMO, Roberto Luiz do Carmo; CARDOSO, Ana Cláudia Duarte; DAGNINO, Ricardo de Sampaio; EL SAIFI, Samira; BASTOS, Ana Paula Vidal; CAPARROZ, Márcio Batista; SILVA, Carla Craice. Mobilidade pendular na Região Metropolitana Ampliada de Belém. In: CARDOSO, Ana Claudia Duarte, LIMA, J. J. F. (Org.). Belém: transformações na ordem urbana. 1. ed. Rio de Janeiro: Letra Capital: Observatório das Metrópoles, 2015. p.121-142.

CASTRO, Carlos Jorge Nogueira de. Transporte Público de Passageiros: uma análise sobre as Territorialidades das empresas de ônibus urbano regulamentadas na Região Metropolitana de Belém (2000-2012). 2015, 159f. Dissertação (Mestrado em Geografia) - Universidade Federal do Pará - Programa de Pós-Graduação em Geografia, Belém.

CASTRO, Carlos Jorge Nogueira de; LOPES, Francisco de Assis da Silva; GONCALVES, Nonato Sousa. A 
expansão da mobilidade do transporte rural e suas interações ao espaço urbano de Castanhal (PA). Revista Geoamazônia, v. 6, p. 177-185, 2018.

CAVALCANTE, Flávia Costa. Metropolização e dispersão urbana na Amazônia: a dinâmica socioespacial do município de Santa Izabel do Pará no contexto da urbanização belenense. 2011. 185 f. Dissertação (Mestrado em Geografia) - Universidade Federal do Pará - Programa de Pós-Graduação em Geografia, Belém.

CAVALCANTE, Flávia Costa. Ultrapassando as Fronteiras da Metrópole: o processo de metropolização e a inserção do Município de Santa Izabel do Pará na região metropolitana de Belém. In: TRINDADE JUNIOR, Saint-Clair Cordeiro; SANTOS, Tiago Veloso (Orgs.). O urbano e metropolitano em Belém: (Re)configurações socioespaciais e estratégias de planejamento e gestão. $1^{\mathrm{a} e d .}$ Rio de Janeiro: Consequência, 2019, v. 1, p. 41-54.

CORREA, Roberto Lobato. A periodização da Rede Urbana da Amazônia. Revista Brasileira de Geografia, Rio de Janeiro, v. 49 n. 3, p. 39-68, 1987.

CRUZ, Sâmia Karollyne Moura. Desigualdade Socioespacial e Produção da Moradia: uma análise a partir do Programa Minha Casa Minha Vida na Cidade de Castanhal, Pará. 2019, 140f. Dissertação (Mestrado em Geografia) - Universidade Federal do Pará - Programa de Pós-Graduação em Geografia, Belém.

FERRAZ, Antonio Coca; TORRES, Isaac Espinoza. Transporte Público Urbano. 1. ed. São Carlos: Rima Editora, 2001. 366p

GUILHERME JUNIOR, José Antônio. Reprodução camponesa em área de assentamento na Amazônia: um estudo no Assentamento João Batista II, Castanhal - Pará. 2013. 109 f. Dissertação (Mestrado em Geografia) - Universidade Federal do Pará - Programa de Pós-Graduação em Geografia, Belém.

HENRY, Etienne. OnibuCad, cadastramento tipológico e dinâmica de escala da viação. In: BRASILEIRO, Anísio. HENRY, Etienne (Org.). Viação Ilimitada: Ônibus das Cidades Brasileiras. São Paulo: Cultura Editores Associados, 1999, p.233-282.

INSTITUTO BRASILEIRO DE GEOGRAFIA E ESTATÍSTICA. Panorama de Cidades. Disponível em: https://cidades.ibge.gov.br/brasil/pa/castanhal/panorama - Acesso em: 09/04/2020.

INSTITUTO BRASILEIRO DE GEOGRAFIA E ESTATÍSTICA. Panorama de Cidades. Disponível em: https://cidades.ibge.gov.br/brasil/pa/santa-izabel-do-para - Acesso em: 09/04/2020.

LEANDRO, Leonardo Milanez de Lima; SILVA, Fábio Carlos da. A estrada de ferro de Bragança e a colonização da zona bragantina no estado do Pará. Novos Cadernos NAEA, v. 15, n. 2, mar. 2013, p.143174

LENCIONI, Sandra. Metropolização do espaço: processos e dinâmicas. In: FERREIRA, Álvaro; RUA, João; MARAFON, Glaucio José; SILVA, Augusto César Pinheiro da (Orgs.). Metropolização do espaço: gestão territorial e relações urbano-rurais. Rio de janeiro: Consequência, 2013, p.17-34.

LOPES, Francisco de Assis da Silva. A expansão da mobilidade do transporte rural e suas interações ao espaço urbano de Castanhal. 2019, 82f. Trabalho de Conclusão de Curso (Licenciatura em Geografia) Universidade do Estado do Pará, Centro de Ciências Humanas e Sociais, Igarapé-Açú.

MARCONI, Marina de Andrade; LAKATOS, Eva Maria. Metodologia Científica. 7.ed. São Paulo: Atlas, 2019, 373p. 
MAMANI, Hernan Armando. Alternativo, informal irregular ou ilegal? O campo de lutas dos transportes públicos. In: RIBEIRO, Ana Clara Torres (Org.). El Rostro Urbano de América Latina. Buenos Aires: Clacso, 2004, v. 1, p. 321-346.

MONTEIRO, Alda Selma Frota. Turismo e mudança social na Comunidade do Caraparú - Santa Izabel do Pará. 2003. 75 f. Dissertação (Mestrado em Planejamento do Desenvolvimento) - Universidade Federal do Pará - Núcleo de Altos Estudos Amazônico - Programa de Pós-Graduação em Desenvolvimento Sustentável do Trópico Úmido, Belém.

OLIVEIRA, Jairo Garay Ribeiro de. A importância do sistema de transporte coletivo para o desenvolvimento do município de Campo Grande-MS. 2003, 113p. Dissertação (mestrado) Universidade Católica Dom Bosco, Programa de Pós-Graduação em Desenvolvimento Local, Campo Grande.

RENDEIRO, Carla Blanco. Mobilidade Urbana e Federalismo: repartição de competências e matéria de transporte público coletivo no Município de Belém. 2015, 191f. Dissertação (Mestrado) - Centro Universitário do Pará (CESUPA) - Programa de Pós-Graduação em Direito, Belém.

RIBEIRO, Willame de Oliveira. Centralidade, dispersão metropolitana e interações espaciais: a complexidades dos papéis da cidade de Castanhal na rede urbana do Nordeste Paraense. In: XIV Simpósio Nacional de Geografia Urbana - SIMPURB 2015, Fortaleza. Anais do XIV Simpósio Nacional de Geografia Urbana - SIMPURB 2015. p. 1-20.

RIBEIRO, Willame de Oliveira. Dispersão metropolitana e novas formas urbano-regionais: uma proposta para o reconhecimento e a delimitação da cidade-região de Belém. Ateliê geográfico (UFG), v. 12, p. 132-154, 2018.

SALIM FILHO, Massoud Tufi. Políticas públicas e trabalho no transporte alternativo na Amazônia: Moto-táxi. 2007, 233f. Dissertação (Mestrado em Planejamento do Desenvolvimento) - Universidade Federal do Pará - Núcleo de Altos Estudos Amazônico - Programa de Pós-Graduação em Desenvolvimento Sustentável do Trópico Úmido, Belém.

SANTOS, Karina Pimentel. A produção do espaço urbano e vida cotidiana: uma análise nos diferentes assentamentos urbanos em Castanhal - PA. 2019, 184f. Dissertação (Mestrado em Geografia) Universidade Federal do Pará - Programa de Pós-Graduação em Geografia, Belém.

SANTOS, Milton. A natureza do espaço: técnica e tempo, razão e emoção. São Paulo: Hucitec, 2004, $384 \mathrm{p}$

SANTOS, Milton. O espaço dividido: os dois circuitos da economia urbana dos países subdesenvolvidos. São Paulo: EDUSP, 2004, 433 p.

SENNA, Luiz Afonso dos Santos. Economia e Planejamento dos Transportes. Rio de Janeiro: Elsevier, 2014, 273p.

SILVA, Glauber Ranieri Martins da. Entre Belém e Castanhal: rede de transportes e circuito inferior da economia. 2010. 99 f. Dissertação (Mestrado) - Universidade Federal do Pará - Programa de Pós-Graduação em Geografia, Belém.

SOUZA, Vivian Camila Lobato. Analise Marxista da Mobilidade Urbana na Cidade de Belém-PA: Estudo de Caso dos Bairros da Terra Firme e Guamá. 2015, 198 f. Dissertação (Mestrado em Economia) - Universidade Federal do Pará - Programa de Pós-Graduação em Economia, Belém. 
TRINDADE JR., Saint-Clair Cordeiro da. Das "cidades na floresta" às "cidades da floresta": espaço, ambiente e urbanodiversidade na Amazônia brasileira. Papers do NAEA (UFPA), v. 321, p. 1-22, 2013.

TRINDADE JR., Saint-Clair Cordeiro da. Pensando a modernização do território e a urbanização difusa na Amazônia. Mercator (Fortaleza. Online), v. 14, p. 93-106, 2015.

VALE, Julio Cezar Pinheiro; SALES, Carlo Rafael Lemos. Tempo de Viagem e Frequência de Atendimento: uma análise sobre o transporte público urbano no município de Castanhal - PA. 2016, 60f. Trabalho de Conclusão de Curso (Bacharelado em Engenharia Civil) - Universidade Federal do Pará, Instituto de Tecnologia, Belém. 